\title{
CONFISSÕES DE ANINHA E MEMÓRIA DOS BECOS
}

\author{
Solange Fiuza Cardoso Yokozawa (CAC - UFG)
}

RESUMO: Este trabalho propõe examinar aspectos da poesia memorialística de Cora Coralina e mostrar como esses aspectos conectam a poeta com a modernidade literária. A memória é um dos principais núcleos de criação da obra coralineana, seja a pessoal e artisticamente recriada, seja a "coletiva subterrânea", que a escritora resgata da clandestinidade para inscrevê-la nos autos do passado, reorganizando a história canônica. Ao tecer a sua poesia com os fios do tempo, distante dos centros culturais do país e dona de uma voz individualíssima, a autora encontra a tradição. PALAVRAS-CHAVE: autobiografia; memória coletiva; tradição literária.

Nas palavras dedicadas ao leitor que abrem Poemas dos Becos de Goiás e Estórias mais, primeiro livro publicado por Cora Coralina, diz a autora:

Alguém deve rever, escrever e assinar os autos do Passado antes que o Tempo passe tudo a raso.

É o que procuro fazer, para a geração nova, sempre atenta e enlevada nas estórias, lendas, tradições, sociologia e folclore de nossa terra. (CORALINA 1993: 39)

Ainda nas páginas introdutórias de Poemas dos Becos..., faz a seguinte ressalva:

$$
\begin{array}{r}
\text { Este livro foi escrito } \\
\text { por uma mulher } \\
\text { que no tarde da Vida } \\
\text { recria e poetiza sua própria } \\
\text { Vida. } \\
\text { (CORALINA 1993: 41) }
\end{array}
$$

Essas palavras, que funcionam como um prólogo ao livro, apontam para um dos traços principais da poesia coralineana: a recriação poética do tempo passado, a reinvenção lírica da memória. Essa memória lírica tem, como se pode depreender das citações e confirmar pela leitura da obra, tanto um caráter pessoal quanto coletivo. A escritora tanto transfigura em arte vivências individuais, notadamente a infância da menina mal amada Aninha, dando origem a poemas autobiográficos, às "meias confissões de Aninha", quanto recria histórias, lendas, resgata memórias subterrâneas que não constam nos autos oficiais do passado, de modo a promover um rearranjo da história canônica.

Essa bipartição da poesia mnemônica de Cora em pessoal e coletiva é feita apenas para efeito de sistematização desta leitura, vez que recordações individuais e lembranças coletivas estão intimamente ligadas. A memória grupal se inscreve nas linhas e entrelinhas da poesia confessional do mesmo modo que a leitura que a poeta faz do passado social é, como sói acontecer a toda manifestação artística autêntica, assinalada pela sua pessoalidade. Exemplar desse imbricamento é a moeda "vintém de cobre", que dá nome ao segundo livro da autora, Vintém de Cobre: Meias Confissões de Aninha, e nele aparece como motivo recorrente. Esse leitmotiv pode ser entendido, por um lado, 
como símbolo da infância pobre em economias e afeto de Coralina, quando ela era Aninha, a menina mal amada que vestia "mandrião de saias vermelhas" e "timão de restos de baeta", a menina que, sob a caçoada das colegas de escola, "guardava cinquinho e cinquinho / na esperança irrealizada / de inteirar quinhentos réis" (CORALINA 1993: 59). Por outro lado, o vintém pode ser tomado, numa cidade que se formou sob o ciclo do ouro, como símbolo da penúria a que Goiás se viu reduzida após o esgotamento aurífero no século XVIII; penúria que foi reforçada, na geração a que Coralina pertenceu, pela abolição da escravatura.

Vintém de Cobre: Meias Confissões de Aninha constitui a obra declaradamente autobiográfica da poeta, ainda que textos fundados em experiências particulares possam ser lidos em todas as suas publicações. Nesse livro, a autora demonstra ter consciência, através do adjetivo que antepõe a "confissões", das verdades partidas, dissimuladas, esparsas, que ela é capaz de confessar. Isso não só porque quem revela o vivido narra, além do que aconteceu, o que poderia ter acontecido, o que sonhou, imaginou, desejou, de modo a fazer do passado uma invenção do presente. Mas também porque, segundo a escritora, a conveniência, o preconceito, o medo dos vivos, dos mortos e de si mesma, as covardias retardadas e presentes, a tornam capaz de fazer apenas confissões pela metade, impossibilitando-a "de despedaçar a rede / onde se debate o escamado da verdade" (CORALINA 1995: 146).

Entre o que é possível revelar está o que precisa ser desvelado, o que parece causar um mal-estar na poeta porque ainda está mal dito, o que ela bem dirá através do discurso poético para convertê-lo em um bem-estar. Assim, em Vintém de Cobre..., Cora confessa, conforme se lê na apresentação do livro: "Alguma coisa, coisas que me entulhavam, me engasgavam / e precisavam sair" (CORALINA 1995: 43). . De fato, freqüentemente, nesse livro, a autora parece encontrar numa auto-análise, notadamente na análise psicológica da infância, a matéria nuclear de sua criação, dando origem a poemas altamente catárticos. Alguns textos de Poemas dos Becos..., como "Antigüidades", "Minha Infầncia" e "Vintém de Cobre", já apontam para a recuperação freudiana da infância perdida, mas nem sempre amada.

Esse resgate do passado constrói uma visão da infância diferente daquela edificada, sobretudo, pelos românticos e por muitos poetas do século XX, que reiteradamente tomam essa idade como um espaço privilegiado com o qual o artista pode manter uma correspondência feliz, em detrimento ao ingrato presente. Assim, enquanto para poetas como Casimiro de Abreu, Manuel Bandeira e Mario Quintana, a infância, ainda que inventada, é o paraíso perdido, o tempo para sempre amado, o espaço por excelência da saudade, para Cora Coralina, ela não constitui normalmente um reduto de felicidade, de amor e de saudade, de modo que a poeta, a exemplo de Graciliano Ramos em Infância, subverte o mito da meninice feliz e saudosa.

Não há uma intenção valorativa ao dizer que Cora subverte um imaginário recorrente de infância. A visão lírica e a concepção irônica de tempos pretéritos são formas diferentes, mas igualmente válidas, de reconstruções do passado. A eleição da puerícia como uma época de felicidade plena e, portanto, de saudade, parece ser corolário da fratura que se opera entre o artista e a modernidade. Não conseguindo se integrar na sociedade burguesa, não encontrando ressonâncias para sua arte na cidade modernizada, desacreditado do progresso técnico e científico, sofrendo as conseqüências dessas e de 
outras fraturas tais que, o artista busca, freqüentemente, em sua criação, recuperar um tempo em que ainda não houvesse se manifestado essa cisão entre o eu e o mundo. Floresce, assim, abundantemente, a recriação poética de um passado, notadamente a infância, em que é possível viver em estado de graça, com o qual é possível manter uma relação de fusão para resistir simbolicamente ao desencantamento do mundo. A recordação poética da meninice feliz seria, assim, uma das possibilidades de manifestação daquilo que Octavio Paz (1984) denomina "analogia". A analogia e a ironia, modos diferentes de negação da modernidade, constituiriam, segundo Paz, os dois princípios básicos a partir dos quais se estrutura a lírica moderna. A ironia representaria a manifestação deliberada da fissura entre o ser e o mundo moderno. A "analogia", a busca de um mundo em que não houvesse se manifestado essa fissura. No caso de muitos artistas modernos, a analogia recebe amiúde o nome de infância. Cora insere a fratura, a ironia, nesse espaço por excelência de correspondência, de amor e de saudade, como se pode ler no fragmento que se segue de "Menina mal amada":

Eu era uma pobre menina mal amada.

Frustrei as esperanças de minha mãe, desde o meu nascimento.

Ela espera e desejava um filho homem, vendo meu pai doente

irreversível.

Em vez, nasceu aquela que se chamaria Aninha.

Duas criaturas idosas me deram seus carinhos:

Minha bisavó e minha tia Nhorita.

Minha Bisavó me acudia quando das chineladas cruéis da minha mãe.

No mais, eu devia ser, hoje reconheço, menina enjoada, enfadando

as jovens da casa e elas se vingavam da minha presença aborrecida,

me pirraçando, explorando meu atraso mental, me fazendo chorar

e levar queixas doloridas para a mãe

que perdida no seu mundo de leitura e negócios não dava atenção.

Quem punia por Aninha era mesmo minha bisavó.

Me ensinava as coisas, corrigia paciente meus mal feitos de criança

e exortava minhas irmãs a me aceitarem.

Daí minha fuga para o enorme quintal onde meus sentidos foram se aguçando

para as pequenas ocorrências de que não participavam minhas irmãs.

(...)

Chamavam, mãe: vem ver Aninha...

Mãe vinha, ralhava forte.

Não queria que eu fosse para o quintal, passava a chave no portão.

Tinha medo, fosse um ramo de loucura, sendo eu filha de velho doente.

Era nesse tempo, amarela, de olhos empapuçados, lábios descorados.

Tinha boqueira, uma esfoliação entre os dedos das mãos, diziam: "Cieiro".

Minhas irmãs tinham medo que pegasse nelas.

Não me deixavam participar de seus brinquedos.

Aparecia na casa menina de fora, minha irmã mais velha passava o braço

no ombro e segredava: "Não brinca com Aninha não. Ela tem Cieiro

e pega na gente."

Eu ia atrás, batida, enxotada.

Infância... Daí meu repúdio invencível à palavra saudade, infância... 
Infância... Hoje, será.

(CORALINA 1995: 116-17)

A infância que nos pinta Cora, sem carinho de mãe e proteção de pai, regada a rejeição e desamor, apresenta cores muito diversas daquela evocada pela pena nostálgica de outros poetas. Vale sublinhar que a infância, na poeta goiana, não é objeto de saudade, mas de uma evocação freudiana. A saudade é uma modulação de amor. Como diz Eduardo Lourenço, ela é "a expressão do excesso de amor em relação a tudo o que merece ser amado" (1999: 13) . A infância daquela que diz ter sido "uma menina mal amada" não merece ser amada. Sua infância não pode ser, portanto, objeto de saudade. Daí o repúdio invencível da poeta às palavras saudade e infância.

Só o que merece ser amado entra no país da saudade, de modo que, em Coralina, são dignas desses sentimentos, sobretudo: Mãe Didi, a ex-escrava que a amamentou e lhe contava estórias de encantamento, a quem a poeta dedica um poema em Meu Livro de Cordel; a bisavó, uma das principais fontes memoriais e afetivas de sua poesia; e mestra Silvina, presença constante na poesia coralineana, a quem a autora dedica Vintém de Cobre... Silvina Ermelinda Xavier de Brito foi a única professora de Aninha, a menina que sentava no banco das mais atrasadas, aquela que, aprendendo a ler e a escrever através da dedicação da velha mestra, um dia se desencantaria em Cora Coralina.

É importante destacar que as confissões de Cora não são um mero derramamento pretensamente sincero de uma alma ingênua e incontida. Suas memórias pessoais são transfiguradas pela arte e qualquer produção digna desse nome é, em última instância, criação, ficção. Seria válido resgatar, nesse sentido, o sempre citado "Autopsicografia", de Fernando Pessoa, que está a nos lembrar que "o poeta é um fingidor / finge tão completamente / que chega a fingir que é dor / a dor que devera sente" (1990: 164) . Nesse poema, o verbo "fingir" não tem o caráter negativo que o senso comum lhe atribui. "Fingir", nesse caso, parece retomar o seu sentido etimológico de criação.Fingo/fingere (fingir), donde teria vindo a palavra latina fictionem, inicialmente tinha o significado de tocar com a mão, modelar na argila. Na Bíblia em latim, o verbo usado para dizer que Deus criou o homem é o verbo fingo/fingere. "Fingir", pois, nos versos pessoanos, pode significar criar, ficcionalizar. Ora, que o poeta seja um fingidor - no sentido de que não precisa haver uma consubstanciação entre viver e cantar, como pretendiam os românticos - é lugar comum nas teorias do texto poético. Mas Pessoa vai além e observa que o poeta, mesmo quando liriciza uma experiência vivida, como faz Cora em seus poemas autobiográficos, deve "fingi-la", ficcionalizá-la, de modo a transfigurá-la em arte, a fazê-la transcender as individualidades.

Exemplar desse fingimento em Coralina é a máscara que ela coloca, é o sujeito lírico que constrói, é a personagem que recria ao poetizar a sua infância: a menina Aninha. A poeta nasceu Ana Lins dos Guimarães Peixoto. Tão logo começou a publicar seus escritos em periódicos, adotou o pseudônimo com que o Brasil a conhece, o qual terminou por suplantar o seu nome de batismo e de registro. Mas ao revisitar poeticamente a infância, não fala em nome de Cora. Cora Coralina é a autora empírica que assina os versos. Nos poemas autobiográficos dedicados à infância, é Aninha a personagem, a persona, a máscara lírica da poeta. Em "Minha Cidade", essa máscara aparece pela primeira vez: "Eu sou aquela menina feia da ponte da Lapa / Eu sou 
Aninha" (CORALINA 1993: 47) . A equação simplista e freqüente do tipo Cora = Aninha pode ser enganosa. O eu poético declara ser Aninha da mesma forma que diz: "Eu sou aquele teu velho muro / verde de avencas", "Eu sou estas trepadeiras sem classe", "Eu sou a dureza desses morros" (CORALINA 1993: 47-48). Trata-se de um processo de composição metafórico recorrente na poesia coralineana. Há uma multiplicidade de "eus" nessa poesia e Aninha é um desses "eus". Um eu de raízes confessionais, é preciso reconhecer, mas que ultrapassa o mero biografismo, que ficcionaliza ou finge, como o quer Pessoa, a sua vivência, a sua dor particular, para convertê-la em experiência poética, em dor do mundo. Dessa conversão, a autora demonstra ter consciência quando, nas páginas iniciais de Vintém de Cobre..., diz estar certa de uma das conseqüências do livro: "muitas dirão: estas coisas também / se passaram comigo" (CORALINA 1993: 43).

A infância triste, cheia de privações da menina Aninha parece ter preparado em Cora Coralina, segundo Carlos Drummond de Andrade (1993: 22), uma percepção solidária das dores humanas. É assim que, ao recuperar literariamente as memórias coletivas do passado, ela privilegia aquelas vidas tão fadadas ao desamparo como foi a de Aninha: o menino lenheiro, "sem infância, sem idade"; a menina Jesuína, abraçada à sua boneca de pano e vítima de uma época em que criança não valia nada; a mulher da vida, "desprotegida e explorada / ignorada da Lei, da Justiça e do Direito"; a lavadeira do Rio Vermelho, "perdida no seu mundo / de trouxas e espuma de sabão"; enfim, a "gentinha" do beco, as vidas subterrâneas que não entraram na história canônica. Exemplar dessa preferência pelas "vidas obscuras" cujos nomes não foram assinados nos autos oficiais do passado é o poema que se segue:

"Todas as vidas"

Vive dentro de mim uma cabocla velha de mau-olhado, acocorada ao pé do borralho, olhando pra o fogo.

Benze quebranto.

Bota feitiço...

Ogum. Orixá.

Macumba, terreiro.

Ogã, pai-de-santo...

Vive dentro de mim

a lavadeira do Rio Vermelho.

Seu cheiro gostoso

d'água e sabão.

Rodilha de pano.

Trouxa de roupa,

Pedra de anil

sua coroa verde de são-caetano.

Vive dentro de mim a mulher cozinheira.

Pimenta e cebola.

Quitute bem feito.

Panela de barro. 
Taipa de lenha.

Cozinha antiga

Toda pretinha.

Bem cacheada de picumã.

Pedra pontuda.

Cumbuco de coco.

Pisando alho-sal.

Vive dentro de mim a mulher do povo.

Bem proletária.

Bem linguaruda,

desabusada, sem preconceito,

de casca-grossa,

de chinelinha,

e filharada.

Vive dentro de mim

A mulher roceira.

- Enxerto da terra, meio casmurra.

Trabalhadeira.

Madrugadeira.

Analfabeta.

De pé no chão.

Bem parideira.

Bem criadeira.

Seus doze filhos,

Seus vinte netos.

Vive dentro de mim

a mulher da vida

Minha irmãzinha...

Tão desprezada,

Tão murmurada...

Fingindo alegre seu triste fado.

Todas as vidas dentro de mim:

Na minha vida -

a vida mera das obscuras.

(CORALINA 1993: 45-46)

Entre todas as mulheres, gênero condenado por longo tempo ao limbo do esquecimento, a poeta se sensibiliza, sobretudo, com aquelas sobre as quais pesa um silêncio ainda maior, aquelas que, além de mulheres, constituem a escória da sociedade a que pertenceu Cora, a cabocla velha, a lavadeira, a cozinheira, a mulher do povo, a mulher roceira, a mulher da vida, de modo a conferir a essas "vidas obscuras" uma dignidade lírica, um caráter heróico.

Ao privilegiar um heroísmo poético que reabilita a periferia, a marginalidade, a clandestinidade, a poesia coralineana reorganiza a história oficial. Interessante nesse sentido é a opção da autora pela palavra estória para denominar a sua produção, seja a vazada em verso ou em prosa. Hoje nos parece imprópria a distinção entre história/estória. Isso porque já caiu no vulgo que a história, mesmo e sobretudo aquela escrita com $\mathrm{H}$, não passa de uma interpretação do passado, sendo, portanto, relativa, ficcional, e que a estória, assumidamente ficcional, muita vez, desvela o passado de uma 
maneira muito mais "verdadeira" que as histórias que se querem factuais. O próprio Aurélio recomenda apenas a grafia história, tanto no sentido de ciência histórica, quanto no de narrativa de ficção, conto popular, e demais acepções. Mas Cora escreve em uma época em que essa diferença ainda é sustentada e a poeta mantém a denominação de estórias para os autos do passado por ela recuperados literariamente. $\mathrm{O}$ termo aparece intitulando dois de seus livros:Poemas dos Becos de Goiás e Estórias mais e Estórias da Casa Velha da Ponte. Em Poemas dos Becos..., ela ressalva que o livro é "um modo diferente de contar velhas estórias". Aqui o modo diferente parece dizer respeito à forma literária, personalíssima, coralineana, com que as estórias de tempos idos são recontadas. No conto que dá nome ao livro O Tesouro da Casa Velha, a "velha rapsoda", a exemplo de Guimarães rosa, põe a "fábula em ata", ao resgatar, através da escrita literária, uma crônica do passado que ouvira de sua bisavó, uma de suas principais fontes mnemônicas: "minha bisavó contava. Não por ela mesma que isso é revelho, de ouvir contar a outra sua bisavó" (CORALINA 2000a: 43-44). Ao evidenciar que a sua fonte é a oralidade, fonte tão confiável (ou suspeita!) quanto outra, a escrita, privilegiada por muito tempo pela história, Cora problematiza a relação entre história e estória, fazendo a sua opção pela segunda:

História mesmo do acontecido, com $\mathrm{H}$, não encontrei em nenhum papel velho amarelado, mas que existiu, existiu mesmo. Minha bisavó, meu avô estavam cansados de contar, e os antigos eram sempre os donos da mentira e da verdade (...) Na falta do exato, forte e bem configurado, conto o que ouvi e a mais não estou empenhada, que história indagada, perquerida, é difícil na minha cidade (...) Nem eu tenho jeito de historiadora. (CORALINA 2000a: 44)

Negando-se a ser uma historiadora e assumindo-se como uma legítima contadora de estórias, a escritora termina por subverter a memória coletiva oficializada, por promover um rearranjo da história tradicional. Parafraseando Guimarães Rosa, pode-se dizer que, em Cora, a estória não quer ser história. A estória, nela, é contra a história. Contra uma história e uma memória coletiva uniformizadoras e opressoras, mas, é preciso que se lembre, irmanada com os modernos estudos de história e de memória. Nesse sentido, é oportuno lembrar um estudioso da área da memória, Michael Pollak. Assumindo posição contrária a Maurice Halbwachs, que acentua as funções positivas desempenhadas pela memória comum, notadamente a de reforçar a coesão social, Pollak acentua o caráter destruidor, uniformizador e opressor da memória coletiva. A esta se oporia a dos marginalizados, a das minorias, as memórias subterrâneas das culturas minoritárias e dominadas. Transmitidas de geração a geração oralmente e não através de publicações, essas memórias prosseguiriam seu trabalho de subversão no silêncio: "o longo silêncio sobre o passado, longe de conduzir ao esquecimento, é a resistência que uma sociedade civil impotente opõe ao excesso de discursos oficiais" (POLLAK 1989: 5). Ao aludir ao silêncio dos judeus sobreviventes ao Nazismo, observa Pollak: "Para poder relatar seus sofrimentos, uma pessoa precisa antes de mais nada encontrar uma escuta" (1989: 6) . Coralina parece ter sido a escuta mais eficiente das memórias subterrâneas dos becos de Goiás. Pertence ela àquela categoria de indivíduos que, ainda segundo Pollak, teimam "em venerar justamente aquilo que os enquadradores de uma memória coletiva em um nível mais global se esforçam por minimizar ou eliminar" (1989: 12). 
Ao reverenciar as memórias ocultas, a poeta não reorganiza apenas a história oficial, mas também o heroísmo da poesia épica e, ao fazê-lo, assume uma atitude poética que a conecta com a modernidade literária. Nesse sentido, Walter Benjamin (1989: 73), ao analisar a figura do herói em Baudelaire, diz que "para viver a modernidade, é preciso uma constituição heróica". Mas o herói épico não tem lugar numa sociedade moderna, de modo que é freqüentemente no lixo da sociedade (BENJAMIN 1989: 78) que o poeta francês o encontra. Cora Coralina, a exemplo de Baudelaire e da tradição moderna, também desentranhou o seu heroísmo do lixo humano, das "vidas obscuras" que a sociedade condenou à clandestinidade dos becos.

No caso do Brasil, essa tendência tornou-se prática consciente e coletiva a partir dos modernistas de 22, que, rejeitando a distinção entre temas poéticos e não poéticos, optaram pela poetização do que até então permanecera fora das esferas poéticas. E o que estava fora dessas esferas também estava, muita vez, fora das margens sociais. É assim que vamos encontrar personagens como o carregador de feira-livre João Gostoso, de "Poema tirado de uma notícia de jornal", de Manuel Bandeira, o moço leiteiro, de "Morte do leiteiro", de Carlos Drummond de Andrade, os indivíduos ínfimos celestados pela poesia de Manoel de Barros, as "vidas obscuras" iluminadas pela lírica de Cora Coralina, enfim, todos esses personagens que representam uma interpretação pessoal, um desdobramento da preferência modernista por poetizar os tipos humanos que até então permaneciam fora da poesia e da vida.

Vale insistir nessa relação da autora com a tradição poética moderna e modernista porque ela é freqüentemente lembrada pelo seu insulamento, pela sua independência em relação a qualquer estilo literário. Ela própria reforça esse mito ao dizer, quando indagada sobre a sua convivência com os poetas modernos brasileiros, que sempre viveu muito isolada literariamente, que lia muito pouco esses poetas porque na sua cidade não tinha livraria e quando viajava não dispunha de numerário para comprar livros (CORALINA 1990).

É verdade que a poeta escreveu o melhor de sua obra quando retornou à Cidade de Goiás, na década de 50, depois de ter passado quarenta e cinco anos no interior e na capital de São Paulo. Nessa época, Goiás, que recentemente havia deixado de ser capital do estado, não era uma cidade que favorecia a comunicação da doceira da casa velha da ponte com o resto do mundo. Mas viver em uma cidade cercada de morros por todos os lados e situada no interior do Brasil não impediu que Cora Coralina fosse lida por um poeta como Carlos Drummond de Andrade, que se encantou com a beleza dos seus versos e os revelou para o Brasil. Também não impossibilitou que ela travasse conhecimento com a literatura de seu país e do mundo, o que está assinalado explicitamente em sua poesia. Em um dos poemas sobre os becos de Goiás, conclama os poetas e pintores surrealistas, concretistas, cubistas a "cantar, rimar em versos, / bizarros coloridos, / os becos da minha terra" (CORALINA 1993: 119). Em Vintém de Cobre..., parodia o Bandeira de "Vou-me embora pra Pasárgada" ao liricizar os "reinos da Cidade de Goiás, onde todos somos amigos do Rei” (CORALINA 1995: 43). Ainda nesse livro, faz alusão a Guimarães Rosa (CORALINA 1995: 168), escritor com quem compartilha o gosto pelo arcaísmo, o aproveitamento e a transformação da matéria regional. Em Meu livro de Cordel, há três poemas dedicados a Pablo Neruda, quando de sua morte. Em entrevista, a mesma escritora que afirma o seu isolamento literário 
reconhece o seu débito para com o estilo modernista: "Eu só me libertei da dificuldade poética depois do modernismo de 22 , mas não acompanhei o movimento - me achei dentro daquela mudança". A libertação aqui diz respeito ao verso livre. Cora Coralina começou escrevendo contos. Foi só depois da libertação formal da vanguarda de 22 que ela passou a escrever versos. Seus versos são exemplares da indistinção tão cara aos modernistas entre a forma da poesia e a da prosa; indistinção de que tem consciência a autora ao fazer a seguinte ressalva em Poemas dos Becos...: "Este livro: / Versos... Não / Poesia... Não. / um modo diferente de contar velhas estórias" (CORALINA 1993: 41).

Assim sendo, apesar de a crítica destacar o desprendimento da poeta de qualquer tradição literária, apesar de ela própria reiterar esse desprendimento, verifica-se que, nos momentos de maior individualidade e originalidade da sua obra, como é o caso de quando canta a "gentinha" do beco da sua cidade, ela fala em uníssono com a modernidade literária e o modernismo brasileiro, de modo a corroborar a tese de T. S. Eliot de que o poeta novo teria os passos melhores e mais significativos não naqueles aspectos de sua obra em que menos se parece com qualquer outro, como gosta de insistir certa tendência, mas naqueles onde "os poetas mortos, seus antepassados, mais vigorosamente afirmam a sua imortalidade" (s.d. 22).

Para finalizar estas considerações, vale lembrar que a memória, em Cora Coralina, é uma memória espacializada, fossilizada no espaço. Bachelard já chamou a atenção para a importância do espaço na preservação dos tesouros dos dias antigos. E o espaço que guarda, por excelência, o tempo recuperado em prosa e verso pela escritora é a Cidade de Goiás, ainda que encontremos textos como "Cântico de Andradina", "Cidade de Santos", "Ode a Londrina" e outros que privilegiam diferentes rincões do Brasil. É verdade que ao perscrutar a memória guardada pela sua cidade, ela apreende uma dimensão humana que desconhece fronteiras regionais, de modo a conferir uma força universal à sua poesia. Malgrado isso, é essencialmente a Cidade de Goiás o espaço memorial de onde desentranha a matéria de sua literatura.

Interessante é que Cora passou parte significativa de sua vida fora de Goiás Velha. Mesmo que ela escrevesse contos desde a adolescência, mesmo que nos tempos em que viveu no estado de São Paulo não tivesse abandonado a escrita, é quando, já viúva e tendo os filhos casados, volta para a sua cidade, para a casa velha da ponte, que ela escreve os versos que chamaram a atenção do país. Esses versos não estão fundados, essencialmente, no que a autora viveu nas terras paulistas. $O$ contato com outros lugares parece ter-lhe amadurecido a inteligência, aguçado a sensibilidade lírica para rever e transfigurar em arte o passado que ela viveu ou ouviu contar e que está comprimido na Cidade de Goiás.

Nos "reinos da cidade de Goiás", dois são os espaços memoriais eleitos pela poeta, a casa velha da ponte e os becos. Para Bachelard, entre todos os espaços mnemônicos, a casa natal assume um papel de destaque, pois é ela que mantém a infância imóvel, é graças a ela que "um grande número de nossas lembranças estão guardadas" (1993: 27). Cora Coralina encontra na casa da ponte, que pertenceu ao seu avô, o espaço primeiro da memória pessoal, das poesias em que revisita freudianamente a infância. $\mathrm{O}$ visitante que vem a Goiás pode entrar nessa casa, percorrer seus aposentos, tomar água na biquinha e contemplar objetos que estão na poesia da autora, como é o caso do prato azul-pombinho, peça central de um belo poema lírico-narrativo. Mas a casa que aparece 
na literatura é mais que essa casa material em que o visitante pode penetrar, é mais que a casa que a poeta habitou na infância e a que regressou decorridos muitos anos de ausência. A casa natal, que guarda a infância, é mais que uma construção feita de taipa e telha, é uma casa-lembrança, que sempre habitou a escritora, mesmo em sua longa ausência, a ponto de ela dizer: "ter dado voltas ao mundo / sem deixar a sua casa" (CORALINA 1993: 193). Talvez mais que uma casa-lembrança, a morada paterna seja, como diz ainda Bachelard, uma "casa onírica", "uma cripta da casa natal", "uma casa lembrança-sonho, perdida na sombra de um além do passado verdadeiro" (BACHELARD 1993: 34). Uma casa lembrança-sonho reconstruída com palavras quando convertida em espaço de memória poética.

Da mesma forma que a casa materna guarda a infância, os becos conservam a memória das "vidas obscuras" resgatada pela poesia coralineana. Se o espaço é o responsável por comprimir o tempo, os becos, esses "vasos comunicantes onde / circulava a vida humilde da cidade" (CORALINA 1993: 117), compõem o reduto da memória grupal eleito por Cora. É esse espaço "estreito e sujo", "esquecido e abandonado" (CORALINA 1993: 119) e não os monumentos, que a poeta revisita através da reminiscência lírica. Beco é lugar onde as famílias vilaboenses jogavam o sem serventia. "Sapatos velhos. Velhas bacias. / Velhos potes, panelas, balaios, gamelas, / e outras furadas serventias" (CORALINA 1993: 109) compunham os monturos dos becos. Beco é lugar de galinha morta, "fedorenta. / Apodrecendo ao deus-dará" (CORALINA 1993: 107), de plantas que "nascem à toa", "sem amparo nem reparo de ninguém" (CORALINA 1993: 111). Nos becos, a sociedade jogava não só as coisas imprestáveis, mas também a escória, o lixo humano, a sujeira da sociedade. Beco é lugar "onde família de conceito não passava. / "Lugar de gentinha", "de gente do pote d'água. / De gente de pé no chão", de "mulher perdida" (CORALINA 1993: 104), de escravos "pulando o muro dos quintais, / correndo pra o jeguedê e o batuque" (CORALINA 1993: 108), de "vidas obscuras".

Em Poemas dos Becos..., a autora dedica três poemas a esse espaço marginal: "Becos de Goiás", "Do beco de Vila Rica", "Beco da escola". Mas mesmo quando recupera outros espaços, quando percorre outra geografia que não a vilaboense, pode-se dizer que a sua poesia é, metaforicamente, uma poética dos becos. É o que acontece, por exemplo, quando visita literariamente o Palácio Conde dos Arcos: "O Palácio dos Arcos / tem estórias de valor / que não quero aqui contar. / Vou contar a estória do soldado carajá" (CORALINA 1993: 129). No paço, a poeta encontra não os governadores de província que por lá passaram, mas o índio carajá, um soldado civilizado que, um dia, tendo seus atavismos despertados por um trovão, despiu a roupa e a civilidade e sumiu-se no rumo do Araguaia. É o que acontece também quando percorre outros sítios, donde desentranha heróis como Lampião (CORALINA 1995: 86), Tiradentes (CORALINA 1995: 131), os judeus errantes (CORALINA 1994: 41-42) e o obscuro Campos Sales (CORALINA 2000b: 17), não o ex-presidente, mas um negro sobrevivente da Guerra do Paraguai.

Cora Coralina, quando regressou à casa velha da ponte, depois de quarenta e cinco anos de ausência, encontrou nela guardada a infância; infância que revisita em versos que subvertem o mito da saudosa meninice feliz. O portão do quintal da casa que fossilizou o passado da poeta, a exemplo de tantas outras moradas de Goiás Velha, tem saída para 
o beco, o Beco da Vila Rica, lugar em que a "menina feia da ponte da Lapa", virada em Cora Coralina, perscrutou as memórias subterrâneas e as inscreveu poeticamente nos autos do passado, de modo a promover um rearranjo da memória coletiva oficializada e a conectar a memória poética dos becos com as avenidas da literatura moderna.

\section{OBRAS CITADAS}

ANDRADE, Carlos Drummond. 1993. "Cora Coralina, de Goiás.” Cora Coralina. 1993.

BACHELARD, Gaston. 1993. A poética do espaço. São Paulo: Martins Fontes. BENJAMIN, Walter. 1989. Charles Baudelaire um lírico no auge do capitalismo. São Paulo: Brasiliense.

CORALINA, Cora. 1990. Depoimento de Cora Coralina a Marlene Velasco. In: VELLASCO, Marlene Gomes de. A poética da reminiscência; estudo sobre Cora Coralina. 1990. Diss. Mestrado em Letras e Linguística, Instituto de Ciências Humanas e Letras, Universidade Federal de Goiás, Goiânia.

—. 1993. Poemas dos becos de Goiás e estórias mais. 18.ed. São Paulo: Global, 1993.

— 1 1994. Meu livro de cordel. 5.ed. São Paulo.

—. 1995. Vintém de cobre: meias confissões de Aninha. 5.ed. São Paulo: Global.

—. 2000a. O tesouro da casa velha. 3.ed. São Paulo: Global.

—. 2000b. Estórias da casa velha da ponte. 9.ed. São Paulo: Global.

ELIOT, T. S. s.d. Ensaio de doutrina crítica. s.l.: Guimarães.

LOURENÇO, Eduardo. 1999. Mitologia da saudade. São Paulo: Cia das Letras.

PAZ, Octavio. 1984. Os filhos do barro: do romantismo à vanguarda. Rio de Janeiro:

Nova Fronteira.

PESSOA, Fernando. 1990. Obra poética. Rio de Janeiro: Nova Aguilar.

POLLAK, Michael. 1989. "Memórias, esquecimento, silêncio." Estudos Históricos (Rio de Janeiro) 2.3. 